\title{
Determination of Cloud Effect on the Performance of Photovoltaic Module
}

\author{
M. H. Ali ${ }^{1}$ and Abdulsalam Ibrahim Gaya ${ }^{2}$ \\ Department of PhysicsBayero University, Kano - Nigeria
}

\begin{abstract}
This letter investigates the effect of cloud on the performance of solar PV panel. The intensity of solar radiation is reduced in cloud condition, because cloud interrupts beam radiation reaching the earth surface as a result, this affect the output performance of the $P V$ module. Outdoor experiment and simulations of parameters of the PV module are conducted using MATLAB to investigate this effect. Result shows that the cloud reducesthe efficiency of the PV module by blocking some part of the Sun insolation. In the three experimental locations of this work, the reduction in efficiency was found to be from $0.96 \%$ to $3.77 \%$.
\end{abstract}

Keywords: Solar energy, Solar radiation, Cloud effect, Photovoltaic (PV) module.

\section{Introduction}

Energy was a great discovery of human being which made our life more and more comfortable[1]. Increasing consumption and demand for energy shows that energy will be one of the major problem in the world[2]. An alternative renewable energy source is the answer. The renewable energy resources are becoming essential factor in power electric generation in many countries. There are various renewable sources which utilized for the production of electric power,such as solar energy, wind energy, and geothermal etc. solar energy is the best choice for electric generation in the countries characterized by an high solar radiation intensity[3].

Solar energy is the energy that is available in the sun light or in the heat generated sun light[4]. Solar energy can play a remarkable role in reducing the destructive effects of fossil fuel exploitation. Solar energy is considered as one of the greatest renewable energy sources due to its accessibility in the most part of the world [5].The solar energy can beharvestedbythree approaches; chemical (photosynthesis),

Thermal(solarheaters)andelectricalenergy(solarcells) [1].The research interests in renewable energy, especially the solar energy, are continuously increasing because of the rising price of traditional energy resources and serious environmental pollution. The solar energy can be study in two ways, the experimental study and the numerical simulation study. Simulations are numerical experiment and can give some kind of thermal performance information as can physical experiments[6].

Over the last 20yrs, the PV industry showed annual growth rates between $40 \%$ and $80 \%$, providing its strength and potential to become a major worldwide power generation source [7]. The working of solar PV panel is totally dependent on the solar radiation falling on it. In normal condition, the radiation which is falling on the panel is global radiation. Global radiation has two major components; one is beam radiation and second is diffused radiation. The beam radiation is direct radiation and it is the major part of radiation which is used to generate electricity[8]. However, in cloud condition, a shadow effect is created which reduces the intensity of solar radiation.

It is well known that the energy conversion efficiency of PV modules depends on a number of different external influences [9]. The design and analysis of PV modules require a tool that can predict the behavior of photovoltaic generators under various weather conditions. Manufacturers usually provide electrical specifications of the PV panels at standard test conditions (STC), namely solar radiation of $1000 \mathrm{~W} / \mathrm{m}^{2}$ and cell temperature of $25^{\circ} \mathrm{C}$. To characterize the performance of a photovoltaic module under varying weather conditions, many models of PV modules have been developed[10], [3], [11]. However, there is need toexperimentally investigate the validity of these models in predicting the performance of photovoltaic module under different climatic conditions.

In this research, we determined the effect of cloud on the performance of photovoltaic module. Although, presence of cloud is statistical, conducting experiment for some days may allow one to have presence of cloud in one or two days, that enables him to identify the quantitative effect of the cloud on the panel function.

\section{Clear sky direct beam insolation}

\section{Background Theory}

Clear flux striking a collector $\mathrm{I}_{\mathrm{C}}$, will be a combination of direct - beam radiation $\mathrm{I}_{\mathrm{BC}}$, that passes in a straight line through the atmosphere to the receiver, diffuse radiation $\mathrm{I}_{\mathrm{DC}}$, that has been scattered by molecules 
and aerosols in the atmosphere, and reflected $\mathrm{I}_{\mathrm{RC}}$, that has bounced off the ground or other surface in front of the collector.

The clear sky insolation reaching the earth's surface (normal to the rays), is given by[12];

$$
\begin{aligned}
I_{B} & =A e^{-k m} \\
\text { Where } ; & A=1160+75 \sin \left[\frac{360}{365}(n-275)\right]\left(w / m^{2}\right) \\
k & =0.174+0.035 \sin \left[\frac{260}{265}(n-100)\right] \\
m & =1 / \beta
\end{aligned}
$$

Total clear sky insolation on a collecting surface

Reasonably accurate estimates of the clear sky, direct beam insolation are easy enough to work out and the geometry needed to determine how much of that will strike a collector surface is straightforward. It is not easy to account for the diffuse and reflected insolation but since that energy bonus is relatively small fraction of the total, even crude models are usually acceptable.

\section{Direct - beam radiation}

The direct beam radiation $I_{B}$ (normal to the rays) into beam insolation striking a collector face $I_{B C}$ is a simple function of the angle of incidence $\theta$ between a line drawn normal to the collector face and the incoming radiation, the incidence angle is given by[12];

$\mathrm{I}_{\mathrm{BC}}=\mathrm{I}_{\mathrm{B}} \cos \theta$

The incident angle is given by[12];

$$
\cos \theta=\cos \beta \cos \left(\phi_{s}-\phi_{c}\right) \sin \Sigma+\sin \beta \cos \Sigma
$$

\section{Diffuse radiation}

The diffuse radiation on a collector is muchmore difficult to estimate accurately than it is for the beam. The radiation can be scattered by atmospheric particles and moisture or reflected from clouds[12].

$$
\begin{aligned}
& I_{D C}=C I_{B}\left(\frac{1+\operatorname{Cos} \Sigma}{2}\right) \\
& \mathrm{C}=0.095+0.04 \sin \left[\frac{360}{365}(n-100)\right]
\end{aligned}
$$

\section{Reflected radiation}

The final components of insolation striking a collector results from radiation that is reflected by surfaces in front of the panel[12].

$I_{R C}=\rho I_{B}(\sin \beta+C)\left(\frac{1-\cos \Sigma}{2}\right)$

Combining the equations for the three components of radiation, direct beam, diffuse and reflected gives the following for total rate at which radiation strikes a collector on a clear day[12];

$I_{C}=I_{B C}+I_{D C}+I_{R C} \quad(2.10)$

$I_{C}=A e^{-k m}\left[\cos \beta \cos \left(\Phi_{S}-\Phi_{C}\right) \sin \Sigma+\sin \beta \cos \Sigma+C\left(\frac{1+\cos \Sigma}{2}\right)+\rho(\sin \beta+C)\left(\frac{1-\cos \Sigma}{2}\right)\right]$

\section{Solar declination}

The angle formed between the plane of the equator and a line drawn from the center of the sun to the center of the earth is called solar declination angle. It varies between the extremes of $\pm 23.45^{\circ}$, and a simple sinusoidal relationship that assumes a 365-day year and which puts the spring equinox on day $n=284$ provides good approximation[12].

\section{Solar position at any time of day}

$$
\delta=23.45 \sin \left[\frac{360(284+n)}{365}\right]
$$

The location of the sun at any time of day can be describes in terms of its latitude angle $\beta$ and its azimuth angle $\varphi_{s}$. The subscript $s$ in the azimuth angle helps us remember that this is the azimuth angle of the sun. By convention, the azimuth angle is positive in the morning with the sun in the east and negative in the afternoon with the sun in the west[12].

Equations of solar angle:

$$
\begin{aligned}
& \beta_{N}=90-L+\delta \\
& \sin \beta=\cos L \cos H+\sin L \sin \delta \\
& H=\frac{15^{0}}{\text { hour }} \text { or } H=\frac{-15^{0}}{\text { hour }}
\end{aligned}
$$


Where $\mathrm{C}$ is the sky diffuse factor, $\Sigma$ is the collector tilt angle, $\rho$ is the ground reflectance, $\Phi_{S}$ is the solar azimuth angle, $\Phi_{C}$ is the collector azimuth angle, $\beta=$ solar altitude angle, $\beta_{N}=$ altitude angle at solar noon, $\mathrm{L}=$ latitude, = solar declination angle, $\mathrm{I}_{\mathrm{B}}=$ beam insolation at earth's surface, $\mathrm{A}=$ apparent extraterrestrial solar insolation, $\mathrm{K}=$ atmospheric optical depth and $\mathrm{m}=$ air mass ratio [12].

\section{One diode PV model circuit}

The simplest model of PV cell is shown as an equivalent circuit below that consists of ideal current source in parallel with an ideal diode [13].

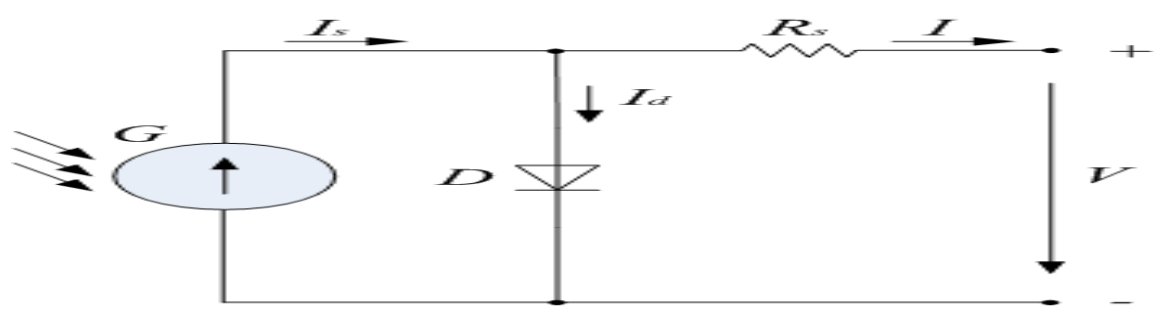

Fig. 1 One diode PV cell equivalent circuit[14].

Where $\mathrm{G}$ is the solar radiance, $\mathrm{I}_{\mathrm{s}}$ is the photo generated current, Rsis the series resistor, Id is the diode current, $\mathrm{I}$ is the output current and $\mathrm{V}$ is the terminal voltage.

I - V characteristics of the solar cell with single - diode and series resistance are given by;

$$
I=I_{S}-I_{O}\left[e^{\frac{q\left(V+R_{S} I\right)}{m k T}}-1\right]
$$

The short circuit current $I_{S C}$ is given by;

$I_{S C}=I=I_{S}-I_{O}\left[e^{\frac{q\left(R_{S} I_{S C}\right)}{m k T}}-1\right]$ For $\mathrm{V}=0$

The open circuit voltage $V_{O C}$ is given by;

$V=V_{O C}=\frac{m k T}{q} \ln \left(1+\frac{I_{S C}}{I_{O}}\right)$ For $\mathrm{I}=0$ (2.18)

The output power is given by;

$P=V\left[I_{S C}-I_{O}\left(e^{\frac{q\left(V+R_{S} I\right)}{m k T}}-1\right)\right](2.19)$

The diode saturation current at the operating cell temperature is given by;

$I_{O}=I_{O}^{*}\left(\frac{T_{C}}{T^{*}}\right)^{3} e^{\frac{\varepsilon q}{m k}\left(\frac{1}{T^{*}}-\frac{1}{T_{C}}\right)}$

Where $I_{C}^{*}$ the diode saturation is current at reference condition, $T_{C}$ is the pin junction cell temperature, $T^{*}$ is the cell $\mathrm{p}-\mathrm{n}$ junction temperature reference condition, and $\varepsilon$ is the band gap [14].

\section{Methodology}

The study was carried out in two ways; Experimental and Simulation. The experiment was conducted in three locations at Bayero University Kano, Old Campus; A: Central Mosque (latitude: 11.976801N, longitude: $8.480831 \mathrm{E}$ ), B: Nana Hall (latitude: 11.98295N, longitude: 8.47756E), C: PG Common Room (latitude: $11.98136 \mathrm{~N}$, longitude: $8.47681 \mathrm{E}$ ). The data were obtained using the following procedure;

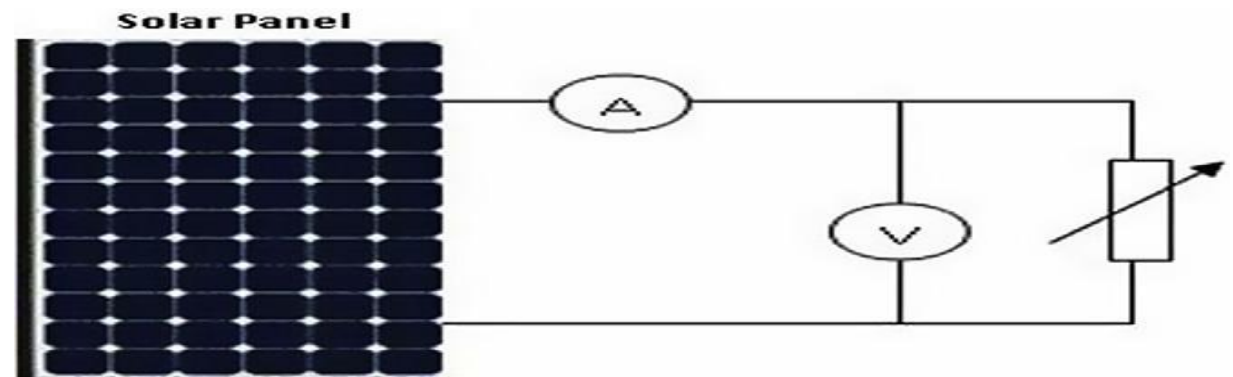

Fig. 2 Experimental set up [10]

The instruments used are Solar panel (YL30P - 17b), Intelligent Digital Multimeter with PC Interface (MAS-345), Rheostat (SR 451) and some connecting wires. The local latitude values for the three locations were used as the PV module tilt angle. The sun azimuth angle of the experimental time was also considered and 
made equal to the azimuth angle of the panel.TheV - I characteristics of the panel was obtained by varying the rheostat in steps. The open circuit and short circuit values were obtained by actually opening and shortening the terminals[10]. In the simulation procedure, Rs PV module single diodemodel was usedand simulated in MATLAB environment. Both the experimental and simulation procedures were carried out for each of the three locations of this research.

\section{Results And Discussion}

The measured PV currents and voltages at each experimental location are plotted. On each plot the simulated values of these parameters are also plotted. Based on the latitude, the day and time of the experiment, the corresponding clear day V - I characteristics of the PV panel was also plotted together. The corresponding $\mathrm{P}-\mathrm{V}$ curves are also plotted on a separate figure.

A.
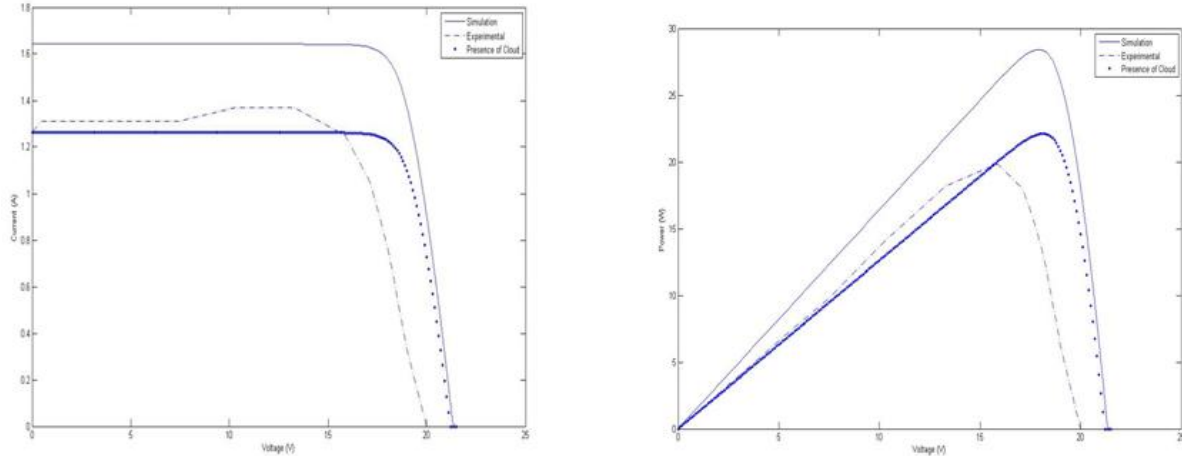

Fig. 1. V-I, P-V characteristics obtained from simulation and experimental study on the day of $9^{\text {th }}$ September 2015 at $9.00 \mathrm{am}$, latitude $=11.98^{\circ}$, tilt angle $=12^{0}$, temperature $=28^{0}$.

B.
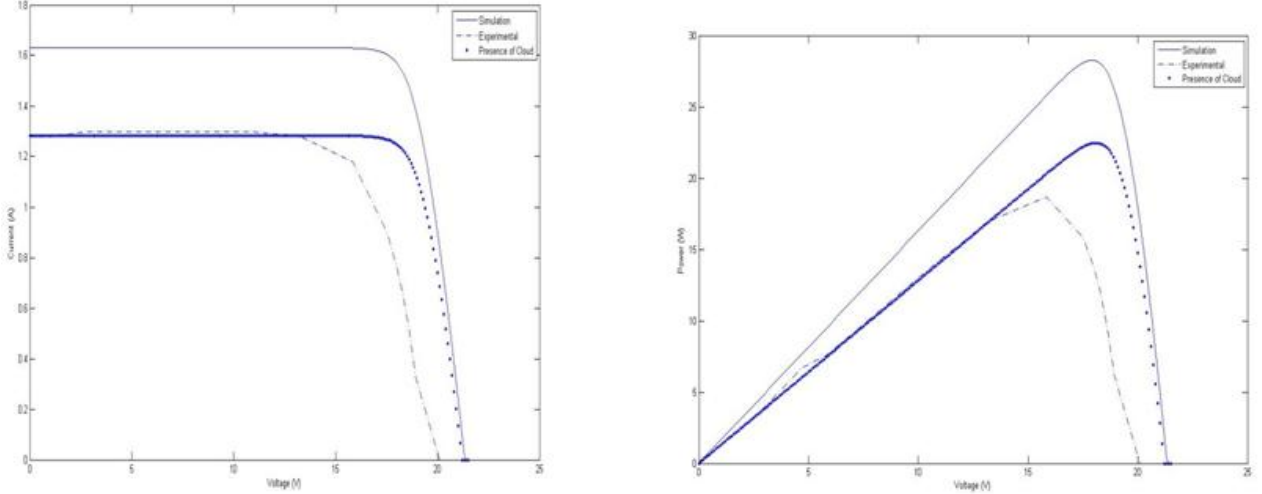

Fig. 2. V-I, P-V characteristics obtained from simulation and experimental study on the day of $4^{\text {th }}$ September 2015 at $9.00 \mathrm{am}$, latitude $=11.98^{\circ}$, tilt angle $=12^{\circ}$, temperature $=28^{0}$.

C.
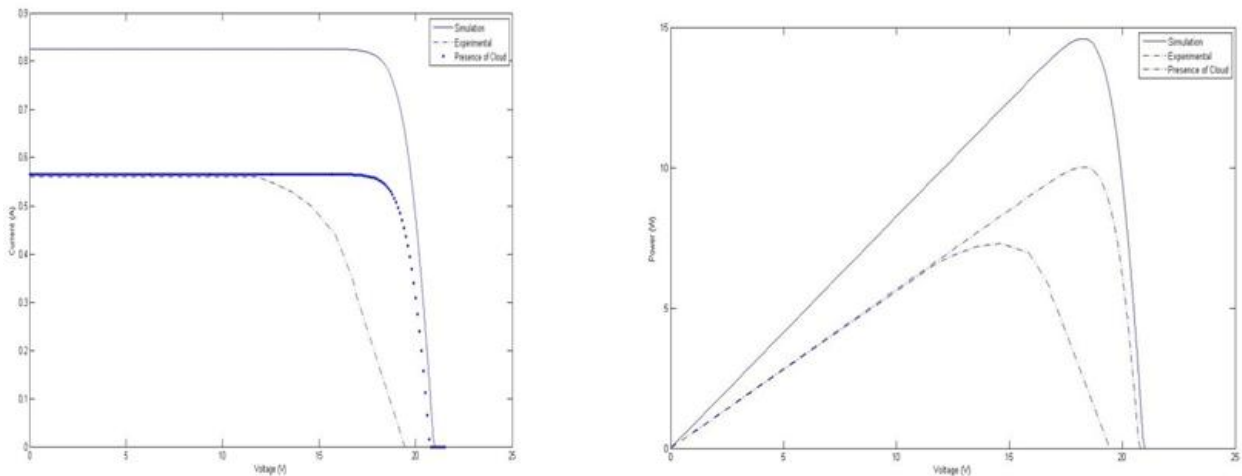

Fig. 3. V-I, P-V characteristics obtained from simulation and experimental study on the day of $8^{\text {th }}$ September 2015 at $12.15 \mathrm{pm}$, latitude $=11.98^{0}$, tilt angle $=12^{\circ}$, temperature $=33^{\circ}$. 
The graphs above (Figure $1-6$ ) are the results of the study obtained from different days and time thatwere chosen from different locations in the Bayero University Kano old campus, in which the experiment was conducted. Each graph presents three curves; simulation (clear day), experimental, and the simulated cloud day. The graphs clearly show that thesimulation strongly agrees with the experimental data. This further validates the relationship of computing cloudless irradiance being used in this research. The irregularities in the experimental curves are due to the presence of cloud in the atmosphere, and the intensity of irradiance is affected by their blockage.

It can observe that the cloudless solar radiation curve is at higher Isc compared to the experimental curve. This shows that presence of cloud in the atmosphere reduces the short circuit current as well as the maximum power of the PV module, which is in agreement with this work.

Table: 4.1Values obtained from experiment for the three locations.

\begin{tabular}{|l|l|l|l|l|}
\hline S/N & LOCATION & LATITUDE & IRRADIANCE $\left(\mathrm{W} / \mathrm{m}^{2}\right)$ & EFFICIENCY $(\%)$ \\
\hline 1 & $\mathrm{~A}$ & 11.976801 & 662.9 & 9.97 \\
\hline 2 & $\mathrm{~B}$ & 11.98295 & 673.6 & 9.25 \\
\hline 3 & $\mathrm{C}$ & 11.98136 & 294.8 & 8.25 \\
\hline
\end{tabular}

Table: 4.2 Values obtained from simulation for the three locations.

\begin{tabular}{|l|l|l|l|l|}
\hline S/N & LOCATION & LATITUDE & IRRADIANCE $\left(\mathrm{W} / \mathrm{m}^{2}\right)$ & EFFICIENCY $(\%)$ \\
\hline 1 & A & 11.976801 & 862.4258 & 10.93 \\
\hline 2 & B & 11.98295 & 856.4575 & 10.93 \\
\hline 3 & C & 11.98136 & 862.4254 & 12.02 \\
\hline
\end{tabular}

\section{Conclusion}

We have found that, cloud reduced the short circuit current (Isc)andmaximum power output (Pmax)as well as the efficiency of the PV module. In this work, the reduction in efficiency at Central Mosque is $0.96 \%$; Nana Hall is 1.68\%; PG Common Room is 3.77\%. The result from simulation and the experiment are in good agreement.However, this can be improved if errors inherent in experimental work are reduced. Thus, the effect of cloud on the performance of PV module has been established.

\section{References}

[1] A. Malviya and P. Prakash, "Photogalvanics : A sustainable and promising device for solar energy conversion and storage," Renew. Sustain. Energy Rev., vol. 59, pp. 662-691, 2016.

[2] S. J. H. Z. Hafiz Bilal Khalil, "Energy crisis and potential of solar energy in Pakistan," Renew. Sustain. Energy Rev., vol. 31, pp. 194-201, 2014.

[3] S. L. Ahmed Bouraiou, Messaoud Hamouda, Abdelkader Chaker, Mohammed Sadok, Mohammed Mostefaoui, "Modeling and Simulation of Photovoltaic and Array based on One and Two Diode Model Using Matlab/Simulink," Int. Conf. Technol. Mater. Renew. Energy, Environ. Sustain. TMREE 15, vol. 74, pp. 864-877, 2015.

[4] S. K. Mohammad Khalil Farooq, "An assessment of renewable energy potential for electricity generation,” Renew. Sustain. Energy Rev., vol. 20, pp. 240-254, 2013.

[5] M. Sabzpooshani and K. Mohammadi, "Establishing new empirical models for predicting monthly mean horizontal diffuse solar radiation in city of Isfahan , Iran," Energy, vol. 69, pp. 571-577, 2014.

[6] C. Shen, Y. He, Y. Liu, and W. Tao, "Simulation Modelling Practice and Theory Modelling and simulation of solar radiation data processing with Simulink," Simul. Model. Pract. Theory, vol. 16, pp. 721-735, 2008.

[7] G. Makrides, B. Zinsser, M. Norton, and G. E. Georghiou, "Performance of Photovoltaics Under Actual Operating Conditions," 2010 .

[8] S. Khandelwal, H. K. Singh, and P. B. L. Chaurasia, "Experimental Study on the Effect of Cloud on Solar Photovoltaic Panel in Jaipur ( Rajasthan )," Inetrnational J. Sci. Res., vol. 3, no. 10, pp. 2012-2014, 2014.

[9] T. Huld and A. M. G. Amillo, "Estimating PV Module Performance over Large Geographical Regions: The Role of Irradiance, Air Temperature, Wind Speed and Solar Spectrum," energies, vol. 8, pp. 5159-5181, 2015.

[10] R. P. Vengatesh and S. E. Rajan, "Investigation of cloudless solar radiation with PV module employing Matlab - Simulink," Sol. Energy, vol. 85, no. 9, pp. 1727-1734, 2011.

[11] J. Bikaneria and S. P. Joshi, "Modelling and Simulation of PV Cell Based on Two-Diode Model,” vol. 11, no. June, pp. 589-594, 2014.

[12] G. M. Masters, Renewable and Efficient Electric Power Systems. New Jersey: John Wiley \& Sons, Inc., Hoboken, New Jersey, 2004.

[13] J. Bikaneria, S. P. Joshi, and A. R. Joshi, "Modeling and Simulation of PV Cell using One-diode model," Inetrnational J. Sci. Res. Publ., vol. 3, no. 10, pp. 1-4, 2013.

[14] E. M. G. Rodrigues, R. Melício, V. M. F. Mendes, and J. P. S. Catalão, "Simulation of a Solar Cell considering Single-Diode Equivalent Circuit Model Key words," Int. Conf. Renew. energies power Qual. Spain, 2011. 